\title{
Technology Resilience and the S.T.O.R.M. Factory*
}

\section{Marco Pironti**, Paola Pisano***, Armando Papa****}

\begin{abstract}
Opportunities opened up by the Industry 4.0 paradigm are related to the acceleration of flexible and open business planning and governance mechanisms to foster the adaptability of the value chain to the rapid changes during ongoing operations by reducing gaps and controlling efforts. The constant search for a dual perspective (short- to medium/long term) and a twofold equilibrium (micro and macro vs. internal and external) is creating new challenges for sustainable business models. The Self-Tuning Open Reengineering Model (STORM) is well suited to explain the organizational behaviours of both industrial and craftsman firms in terms of the strategic and operational aspects of the smart factory paradigm.
\end{abstract}

Keywords: Business Model Innovation; Knowledge Management; Technology Resilience; Lean Factory; Industry 4.0; Manufacturing; The Fourth Industrial Revolution; Global Markets

\section{Digital Technology}

Technology shifting produces a disruptive effect on business models, having revolutionary impacts on internal growth strategies for the manufactures of the future. What follows from this is the search for technological resilience in the organization, i.e. the capability of using technology to restore collaborations when a major environmental disruption is forthcoming (Mark \& Semaan, 2008).

Generally speaking, digital technology defines the new domain of business competition worldwide by transforming the dynamics and the rules within organizations. In particular, employees and leaders have the possibility to rebuild, adjust, and advance in new routines, a new script, and new patterns for work and interactive communication. Thanks to technology, people have the possibility to create new assemblages of digital and physical resources by stimulating fluidity of knowledge within the organization (Del Giudice et al., 2017).

\footnotetext{
* The Authors: M. Pironti § 1,2, P. Pisano § 3,4 A. Papa § 5,6

**Associate Professor of Innovation Management and Entrepreneurship, University of Turin (marco.pironti@unito.it).

***Assistant Professor of Management and Innovation, University of Turin (paola.pisano@comune.torino.it). **** Research Fellow in Management, University of Turin (armando.papa@ unito.it).
}

Edited by: ISTEI - University of Milano - Bicocca

ISSN: 1593-0319

Pironti, M., Pisano, P., Papa A., (2018). Technology Resilience and the S.T.O.R.M. Factory, Symphonya. Emerging Issues in Management (symphonya.unimib.it), 2, 108-124.

http://dx.doi.org/10.4468/2018.2.09pironti.pisano.papa 
$\square$ As a matter of fact, fluidity and resilience have become representative of the new business model, characterized by contextual research of high levels of productivity aimed at increasing the levels of company performance, as well as organizational and managerial flexibility (Vrontis et al., 2017). Hence, the factory of the future looks like a harmonious bundle of resources, leading to greater reliance on virtual work and, in some cases, to deeper structural changes (Black, 1991; Penrose, 2009; Ardichvili et al., 2003).

Therefore, this paper aims at contributing to the leading literature in entrepreneurship, addressing the aforementioned research gap by shedding more light on the issue concerning the digital conversion of business models. In particular, it investigates how knowledge management (KM, one the main aspects of the smart factory) leads to converting enterprises from physical to digital open platform, impacting on innovation performance as well. Regarding KM (which represents a valuable contribution of this paper), the empirical analysis focuses on results achieved by some champion companies that are changing the processes of their manufacturing activities.

$\square$ According to a knowledge-resource base, we can consider a firm's business model as a mix of workers and practices, organizational processes and routines, information and skills, knowledge and innovation (i.e. technology), which characterize the stock of tangible and intangible resources that are essential to achieving competitive advantage (Grant, 1991, 1996; Barney, 2001; Meso \& Smith, 2000; Kearns \& Lederer, 2003).

"Secondly, the concept of STORM, correctly defined as the "SelfTuning Open Reengineering Model," seeks to explain the organizational behaviors of both industrial and craftsman firms in terms of their strategic and operational aspects. It has been designed to strengthen scientific and technological excellence on particular research topics characterized by higher levels of innovation through a lasting integration of innovative and knowledgeable skills of participants (i.e. public and private), and by leveraging network dynamic capabilities within the manufacturing ecosystem".

"In doing so, the entrepreneurial intensity of the Smart Factory can be evaluated independently from the firms' size and physical capital requirements. Hence, we are able to evaluate the competitiveness, not only of large, but also of small and medium companies and to identify as well the re-engineering of processes and models that accompanies the digitizing of organizational structures.

Under these assumptions, the aim of this article is to elaborate a conceptual and practical framework, which capitalizes on the opportunity to extract knowledge from open data and artificial intelligence platforms". 
Following the results, the remainder of the paper is organized as follows: Section 2 proposes the theoretical background regarding knowledge management productivity and lean production as antecedents of smart manufacturing. Subsequently, Section 3 explains the methodology of this study while Section 4 presents the related results. In conclusion, Section 5 presents a discussion of the theoretical and practical implications, emphasizing the role of technology as "accelerator" as well as the conclusions, the limitations of the present research, and perspectives for the future.

\section{Knowledge Management Patterns for Smart Manufacturing}

With the increasing application of Internet of Things and big data analytics to the business model, it becomes essential to implement horizontal and vertical integration of various components inside the factory in order to implement flexible manufacturing configurations of inter-corporation value (Teece, 1998; Del Giudice $\&$ Straub, 2011; Murray et al., 2016). This marks a technological centrality of production processes in innovation strategies (Pisano et al., 2016).

What we know as digital age refers not only to a new vision of smart organization, but also to a link between the crucial characteristics of emerging innovation and communication strategies and those novel manufacturing practices which highlight companies' success with the use of relevant knowledge, thus making it critical in many organizations.

The state of the art ultimately involves discussion of "doing knowledge works," as applied to managerial systems that accompany the digital transformation linked to Industry 4.0. It seemingly recognizes the basis of collaborative cyber-physical systems that represent a future form of industrial network, a moment of Shumpeterian revolution that marks a fundamental passage of creative destruction in the life cycle of businesses and sectors, taking into increase in an hyperbolic way the levels of automation and inter-connectivity of companies, using increasingly intelligent electronic and cybernetic systems (Nelson \& Winter, 1982; Davis et al., 2012; Lasi et al., 2014; Lee et al., 2015).

Although the definition of the knowledge-doing gap is complex and vague in nature, the upgrade approach is based on a dynamic interpretation of the manufacturing execution and a restructuration of human resource policies that involve all organizations which are continuously demanding to extend the boundaries of knowledge works (Iivari \& Linger, 1999). Drucker (1993) could be considered the first scholar defining knowledge works as an environment where people handle information and contents in order to produce outputs (products or services) with knowledge as an essential ingredient. In these meanings, the real matter of knowledge labor concerns its processes and not its results, because we know that knowledge processes are also considered imperceptible and are sometimes defined as service for manufacturing productions (Staats et al. 2011; Laihonen et al. 2012). Such studies (Gupta et al. 2000, Toussaint \& Berry, 2013) acknowledge an overlap between knowledge context and services, thereby extending further the considerations about business activities.

Nowadays, this structural relationship affects organization effectiveness and its assessment becomes a critical research question for the new frontier of Industry 4.0. The larger the firm (and the stronger its connection with technology) the more it is 
likely to set up knowledge management practices. When we define the smart factory as a knowledge-intensive organization, it is essential to recognize the role of knowledge in the working process and how knowledge influences nonreciprocal learning relationships. In effect, the transitivity and proximity of local clustering and aggregation of knowledge and information within sparse intercluster ties are significant for intra-organizational learning networks (Paton et al., 2009; Škerlavaj et al., 2010).

Hence, when a knowledge-intensive organization aims at converting successfully in digitization, it requires high organizational knowledge with strong, collaborative stakeholders and to catch up for new external knowledge (Vrontis et al., 2017).

Drucker (1999) defined six factors to determine knowledge worker productivity: the task at hand, self-management and autonomy, continuous innovation, continuous learning, quality of output (more important than the quantity), and the worker being treated as an intellectual asset.

According to Laihonen et al. (2012), changing ways of measuring productivity in knowledge contexts is not such a big surprise but is the better way to understand and communicate the factors that are impacting on relationship dynamics with customers and the market and for an individual's flexible capability to apply new knowledge to learned experiences (Antikainen \& Lonnqvist, 2006), including the possibility to fund knowledge and skills of learning from the networks (Mårtensson, 2000)..

\section{Lean Productivity, Self-Turning Organization and Knowledge Management Processes}

Empirical evidence shows that technological manufactures can be considered as "lean containers," whose innovation performance in the short as well as medium to long term is closely related to the sustainability of processes and business models that are characterized by organizational ambiguity, i.e. contextual research of high productivity and organizational and managerial flexibility (O'Reilly \& Tushman, 2004, 2008; Raisch et al., 2009; Vrontis et al., 2017).

Consistent with the literature on open data platforms and open system of knowledge (Santoro et al., 2017), the reconversion of the company's engineering and business model aims at featuring the development of technology to create a self-adaptive, open, and dynamic business model that we have appropriately defined as STORM i.e. the "Self-Tuning Open Reengineering Model.

Under these assumptions, we consider a knowledge-skilled organization as an intelligent, self-sufficient, lean, smart, innovative, and versatile environment that is able to replicate, in line with what happens in the competitive environment, the conditions of development and co-creation of value that can be traced back to the paradigms of an innovation ecosystem, with which the company communicates and interacts in an iterative and interactive way, sharing relationships, ideas, and knowledge and endorsing the potential of technological development (Dezi et al., 2018).

$\square$ The STORM approach emphasizes that the main characteristic of a smart factory must be related to its entrepreneurial intensity in exploring the relationship among stakeholder salience, organizational 
posture, and the ability to promote organizational ambidexterity (O’Reilly \& Tushman, 2004; Kuratko et al., 2007; Morris and Sexton, 1996; Raisch et al., 2009).

This introduces a new organizational culture that aims at exploiting technological innovations in the organizational context while also exploring new venture opportunities.

$\square$ Recent empirical evidence shows that technological manufacturers can be regarded as "sleek containers" deemed as a source of innovation performance, a vehicle of digital transformation, and a knowledge management incubator (Zott et al., 2011). All three elements are important components in firms' innovation strategies, with respect to commercialization, trade, and organizational business processes (Rieple et al., 2012; Zott \& Amit, 2008; George \& Bock, 2011; D'Aveni, 2010).

Such an attitude requires the search for "tailor-made" operational strategies that will satisfy those paradigms of efficiency, effectiveness, and affordability and are more accentuated in the digital factory.

In doing so, innovation performance as well as open and self-adaptive business models can represent a turning point for a new competitive formula which emphasizes the excellence of Italian entrepreneurship moving towards new lines of value creation with involve businesses, universities, and public institutions (Mills, 2002; Carayannis \& Campbell, 2009).

Finally, at the organizational and production level, there is a novel stream of research that considers current factories as lean organizational manufactures (Blank, 2012).

In particular, according to Osterwalder and Pigneur (2010), we cannot forget that the contribution of intellectual capital and external knowledge represents the intangible elements of the technological conversion of business models (Foray, 2004). In doing so, the implementation of informatics and cybernetic systems along the entire value chain is considered the first important mediator that supports customer-based and built-to-order competitive logic (Chen \& Popovich, 2003). In particular, big data analytics represents a new era in the exploration and usage of data, especially for the decision-making process and production level that seems to be closest to the market (Zikopoulos \& Eaton, 2011).

This promotes a fluidity in the circulation of knowledge that is useful for strengthening interconnections and human resources relations, thus reacting to and preventing certain organizational dysfunctions. In effect, artificial intelligence systems and Internet of Things (IoT) platforms favor moments of organizational and relationship learning, enhancing exchange of knowledge between people and processes (i.e. human-to-human, human-to-machine, and machine-to-machine) that help to discover, record, store, and transfer technology data (Evans, 2012; Mital et al., 2017).

As a matter of fact, the employee-reskilling of Industry 4.0 aims at extending the traditional skill-set of competencies with a new one built on social skills, organizational leaders, and new workers (Ray, 1989; Barbuto, 2005; Papa et al., 
2018). This mediates between two distinct and mutually exclusive learning modes organizational ambidexterity and search for innovation performance - dealing with the concept of exploration and exploitation routines in knowledge management works (Chesbrough, 2006; Filippini et al., 2012; Vrontis et al., 2017).

Technology-skilled organizations accept for themselves a "thinking ability" not only for employees and managers but also for processes and machineries. According to the principles of Knowledge Management, companies must exploit their intellectual capital, both internally and externally (Brondoni, 2015). Hence, intelligent factories are raised as new best technological transfer practices within the ecosystem with which they interact in order to share and favor new digital knowhow.

\section{Research Approach}

In this paper, we aim to explore the effect of digital transformation on the business model by providing a new conceptual framework that can help scholars and practitioners to understand more deeply how competition and competitiveness play out under the new industrial revolution and formalize some research questions on the new trajectories of business affairs (Freedman, 1999; Friess, 2013).

The literature review done by Datta et al., 2005 has been chosen as the context for this study, serving as the benchmark for the conceptualizations made by the authors.

In this paper, the first hypothesis is:

$\square$ “H1. Knowledge impacts positively on productivity.

This interdependence directly influences the organizational climate by enhancing the communication and interaction between individuals, which is critical for better understanding shared scripts and common vision.

The second hypothesis of our assumptions is:

$\square$ "H2. Technology impacts positively on knowledge interactions, thus becoming a catalytic factor that can help workers to collaborate and to share data and information with each other.

In this condition, the individual with high reward interdependence is more likely to generate a perception of clan culture. And it is also accepted that:

\section{$\square$ H3. Perceived clan culture acts as a mediator in the link between technology upgrade and knowledge hiding.}

In other words, technology transformation brings incentive mechanisms for both more productive and skilled behaviors.

However, the new Smart Factory conceptual framework is hardly generalizable because its application is very much constrained by firms' idiosyncratic characteristics. 
Based on the Business Canvas Model (Osterwalder and Pigneur, 2010) and according to a knowledge management perspective, in Figure 1 we present the STORM framework that aims at considering the smart factory as an open system of knowledge (Berchicchi, 2013; Papa et al., 2018).

In doing so, we want to examine different sources of knowledge (i.e. ingredients) and the key outputs related to technological transformation of the factory.

In particular, we focus on studying how lean methods, functions and business reengineering processes have been affected by digital conversion with the impacts on efficiency and organizational effectiveness and possible reflections on company performance strategies as well (Kuratko \& Audretsch, 2009).

$\square$ We work with three main assumptions:

1) knowledge management is the starting point for creating customer value;

2) customer data and content support digital manufacturing in creating new things; and

3) new things enhance knowledge productivity, developing new competence and expertise.

Accordingly, we are not interested in studying specific organization contexts. Rather, our more general purpose is to highlight the potential use of a new framework for practitioners and academics that could be helpful for understanding digital business realities (see Figure 1 for a research process illustration).

In the next section, we summarize and discuss the state of the art by providing some considerations on implementing smart manufacturing practices on business models, and then conclude with some practical and theoretical implications that could be especially helpful for future works.

Figure 1: The Concept of Storm

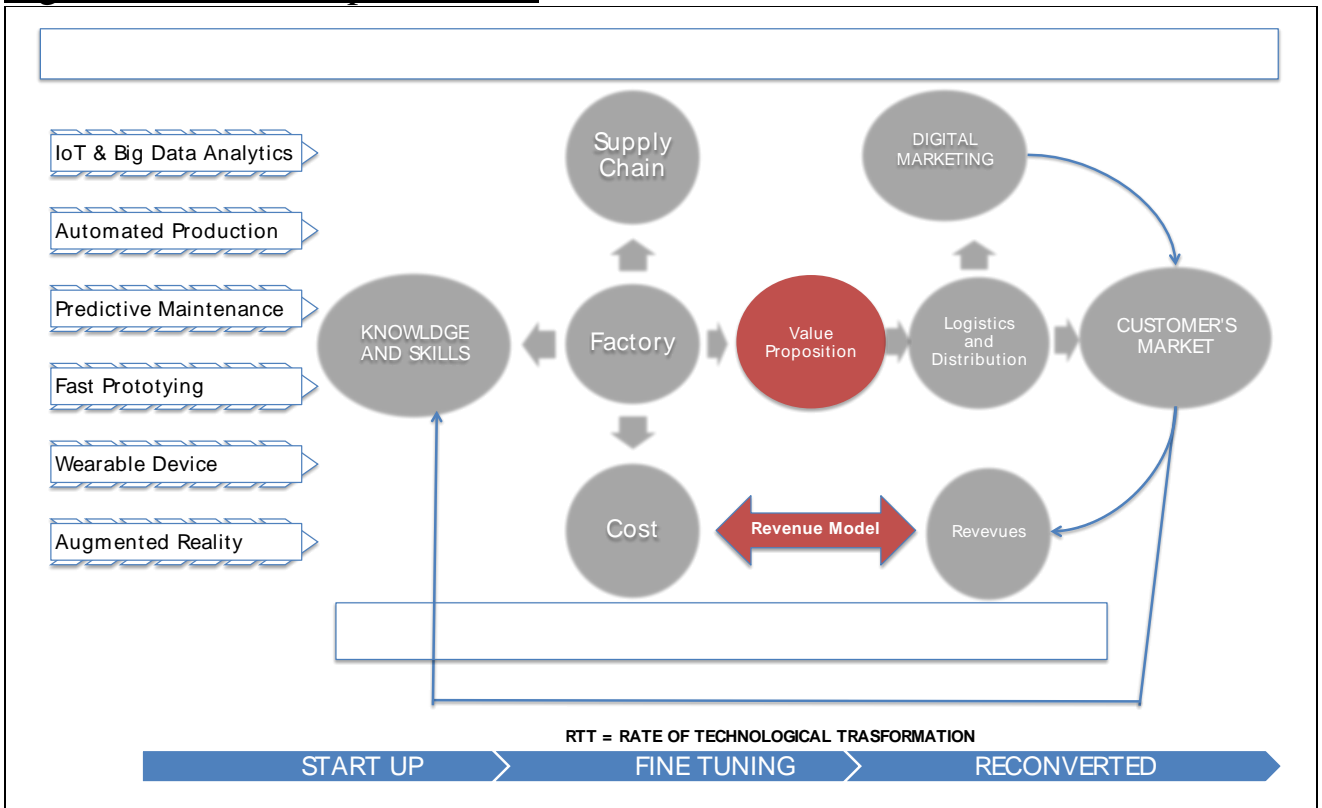

Source: Own Elaboration 


\section{STORM Principles and Approaches to Industry 4.0}

Generally speaking, STORM aims at developing an organizational structure in which intelligent objects and their interconnection processes between the real and virtual domains appear as central aspects of the entire production processes. It is mainly characterized by bottom-up approaches, which are recomposed at the lowest levels of the value-driven pyramid - the shop floor - wherein middle management is positioned to operate in a proximate position with respect to production lines, having the possibility of monitoring and evaluating faster and more effectively the implementation of operating strategies. Hence, it leans towards more specific and faster solutions to resolving manufacturing problems that can hardly be addressed according to standards and best practices replicable in other business organizations.

According to the existing literature, the new paradigm goes beyond the common conceptualization of business models by considering the digital factories not only as "manufacturers," but mostly as "service agglomerates" offered to the customer that will cover industry with ever more labile boundaries.

This approach fosters two main contributions that this paper aims to evaluate: a) the impact on business of the enabling technology model for each participant, and b) those mechanisms, evolutionary stages, and areas affected by the business models' fine-tuning process (Eisendhardt, 1989).

The re-engineering of the smart factories as it means implicitly accepting the management of knowledge and technological innovation is a complex and multistakeholder process; thus, it is very difficult for this process to be managed by each firm as a standalone.

This consideration leads to an understanding of the digital ecosystem, identifying a set of core generative and underlying structural relationships between the factory and its principal partners which fully claim their role in strategic decision making.

$\square$ As a matter of fact, firms reveal the need to propose "modularity" in
their business models, approaching the business as a "fair
compromise" between significant and continuous learning adaptions
(that derive from the business analytics) and the entrepreneurial
investigation of real options strategies according to the interpretive
dogmas of discovery-driven management (McGrath \& Mac Millan,
2009).

As a consequence, firms have to identify the conversion rate and the stage of technology transformation before claiming their value proposition. However, such a process cannot be designed a priori; rather, it follows a deductive approach, aiming at verifying what objectives have been achieved and at what rate of technological transformation (RTT) companies have arrived.

With regard to the innovation grade, it is possible to identify three incremental trajectories of the technology conversion that are following.

A first step identify companies are using IoT machine-to-machine and cloud computing technologies. In this case, we consider factories that are redefining their business logics thanks to the ability to increase the computing power and connectivity of their organizational structures as well as the storage of new 
information. These trajectories can be developed in the short to medium term and require intervention in the application of already developed technologies.

On the other hand, the factory can benefit from analytics skills that can come from machine learning, favoring knowledge sharing and data analysis according to the paradigm of lifelong learning processes. It is also useful to disseminate best procedures and synchronize routines at all organizational levels, by supporting autopoietic knowledge management circuits (Carayannis \& Campbell, 2009).

Subsequently, at the middle stage, we will find companies able to develop interactions between man and machine, involving touch interfaces and augmented reality in manufacturing processes. This stage emphasizes practices of shop floor management and management-by-objectives (MBO) approaches, allowing a monitoring and correction process of real-time performance.

The last evolution stage, the top level, would concern the digital manufacturing processes that include additive manufacturing, new digital technologies, machineto-machine robotics that support smart-working and smart-production processes, rationalizing costs and production times while at the same time optimizing performance and reducing waste and defective products (Westkämper, 2007).

Obviously, the greater the tacit knowledge, the higher will be the impact of technology on business model practices. Accordingly, at this stage it is also useful to identify which level of reengineering business architecture is carrying on its lifecycle. As highlighted by the RTT chart in Figure, we have discovered three main steps of technology transformation, namely startup, fine-tuning, and reconverted.

In the startup, factories pushing a deep transformation of their business models require strong investments in technologies and intellectual capital assets. In this phase, the conversion is planned with other stakeholders. Digitization proceeds slowly and usually in accordance with public fundraising research activities (Romano et al., 2018).

Fine-tuning is an incremental step concerning companies already actively involved in business model conversion. These structures deepen daily technology challenges by directing their knowledge works towards new technology innovations. In contrast with the first step, fine-tuning represents a stage of deep uncertainty and volatility involving the organization at the top management level for strategy as well as from bottom-up in system operations. At this stage, there is a strong impulse for self-assessment (learning by doing), and it almost always proceeds by trial-and-error mechanisms.

Finally, we find factories that have completely reconverted their production into new digital mindsets and reformulated their business model under the thrust of new innovation trajectories. In doing so, we catch technological pioneers, i.e. companies distinguishable for their size and entrepreneurial skills, having already assimilated and overcome the long and tortuous phase of technological transition.

According to global and digital competition, it's easy to understand why every factory should tend to the last stage in the long run. However, this stage is currently still unexplored. This happens because Industry 4.0 requires a new business structure - open, borderless, and elastic - which descends to lean production and informal management with the contents of the new digital entrepreneurship. 
As a matter of fact, a company that proves itself to be "agile" in partnerships or relational networks is also "fluid" in developing harmonious bundles of knowledge and skills aiming at reaching inexorable processes of value co-creation with the ecosystem.

Our consideration are obviously not without limitations. First of all, we consider digital conversion as exogenous an event, neglecting the entrepreneurial intensity of the individual partner who has the opportunity to establish when, where, and how to operate in order to strengthen its innovation performance (Santoro et al., 2017). Secondly, the specialties of a manufacturing industry (e.g., craftsmanship or luxury production) are often the most penalized in terms of efficiency, engaging more frequently in collaborations with the market (Bonfanti et al., 2015). In these cases, customers would provide a greater source of big data analytics, thus liquefying the flow of knowledge within the organizations.

\section{Discussion and Conclusion.}

The innovation of 4.0 lies in knowing how to combine different technologies integrating the factory system and supply chains in such a way as to create a totally connected and integrated system. In doing so, it will be possible to manage networks that incorporate and integrate machinery, plants, and production facilities with logistics, warehousing systems, distribution, and communication channels.

In conclusion, this study deems that digital transformation serves as forerunner to the construction of a new conceptual and practical framework which revises the dynamics of competition based on entrepreneurial intensity (Morris \& Sexton, 1996).

This research aims to understand how the disruptive innovation promoted by Industry 4.0 fosters open innovation practices, developing a conceptual business model which hypotheses a technology resilience for the smart factory, namely a new way of organizational flexibility that highlights the role of knowledge management capabilities.

In particular, a baseline hypothesis has been firstly proposed about the positive effect of knowledge fluidity on the business model. Then, it was hypothesized that the reengineering of processes has an impact on the relationship between the business model and innovation performance. According to the results, we want to support from one side new principles of knowledge management works and the reskilling of competences which can influence the ambidexterity, namely how digital factories are able to pursue the exploitation and exploration of new technological innovations together. Moreover, thanks to IoT and big data analytics, organizations can improve the level of commitment and understanding of the market competition and customer needs as well. In this way, employees are more willing to include external sources of knowledge, and support customer-centric and just-in-time manufacturing solutions (Harrison, 1992; Swanson \& Lankford, 1998; Galbraith, 2011). It is therefore clear that the most precious resource is the amount of data produced by IoT devices. Such data must be accessible by other systems, including stakeholders, users themselves and, if possible, the research communities and institutions as well. To realize this knowledge accumulation, it is necessary that all the devices be connected to the network. 
To really understand if an identified need can be solved by the chosen technological solution, it is necessary to develop several prototypes. The more quickly those prototypes can be developed, the more it is possible to experiment and develop distinctive skills. To achieve this goal, one must be able to identify needs, develop prototypes, and attain an entrepreneurial mentality, which means acting as a startup. Last but not least, it is necessary to create an open organization able to capture opportunities, discover external talents, and inspire and motivate people (Barbuto, 2005).

From a practical viewpoint, we can summarize the implications of this article in two major strains that turn the attention to new modes of competitiveness at the firm and industry level.

First of all, STORM has an impact primarily on the attractiveness of the sector, because companies develop and stimulate competition with different strategies, skills, and models. In doing so, the pursuit of these benefits can have economic implications for: a) improved work productivity based on product innovation capacity, which leads factory to the increase excellence of their knowledge operations (seen as revenue from new products); b) greater efficiency in the use of productive factors (capital, work, and physical assets); and, finally, c) greater product and service quality.

Furthermore, STORM affects key-drivers of the value chain by better linking the manufacturing processes to the stakeholders' needs (Porter, 2008). This also protects the value of innovation, making it difficult to imitate, thus maintaining market share and increasing market penetration.

Consequently, STORM helps top managers to identify new strategic excellence for the organization, by impacting on the acquisition of new markets and creating new product and process innovation.

The challenges of smart implementation in manufacturing industries are overwhelming. As such, it is widely known that successful implementation requires a deep understanding of contextual factors.

To succeed shortcuts and short-term formulas do not help rather, we need to understand both the variation of the knowledge and what we intend to make digital in the factory with much investment, effort, and courage.

When we discuss digital models, the focus is on the knowledge process and related practices. Thus, continuity is fundamental. However, we need to do it quickly, not only thinking about restoring efficiency or chain integration issues.

Regardless of core assets and core business activities, smart organizations have the possibility to eliminate bottlenecks and to create blue ocean businesses that not only have uncontaminated market boundaries but also create new modus operandi (Leonard-Barton, 1992).

$\square$ On the other side, at firm level we recognize human-machine interaction as the most important lever in extracting data and knowledge which is focused on an increasingly active role for workers. They are considered in the same way as entrepreneurs, producers, and generators of innovative solutions and new entrepreneurial ideas. 
According to feelings of ownership with respect to the company in which they work, when it comes to the digital, a knowledge worker could potentially provide useful methods and practices for maintaining knowledge work productivity. In doing so, we celebrate the organization as an incubator of different skills and knowledge.

In conclusion, the factory of the future will be able to "learn to make mistakes." Technology upgrade certainly represents a first tool of responsiveness that allows firms to fail: the risk of default is inversely proportional to the ability to adapt. Awareness is strategic: making Industry 4.0 surely means using digital technology, but also knowing how to read new business (Zuehlke, 2010). And it is precisely in this that skills and knowledge become trigger assets for reconversion. That brings us back to the focal point, namely the shifting of corporate culture, which is the real challenge of Industry 4.0. It happens because, from one side, culture influences the correct implementation of digital technology in organization While, from the other side, it improves the speediness and degree of adaptability of the business model, facilitating self-tuning fittings.

From the theoretical perspective, the existing literature does not satisfactorily investigate the contingent factors regulating the workings of smart factories (Dezi et al., 2018). Accordingly, this study aims at providing a new and original contribution to the main field of research, by addressing several questions and new research idea for the future.

The new concept of the STORM Factory stresses the centrality of new technologies within production processes. Innovation strategies must be able to develop knowledge procedures consisting of external and internal data and information flows that are able to ensure sustainable, unique, and scarcely replicable competitive advantages in order to become more adherent to the competition dynamics in the wake of the Industry 4.0 paradigm (Carayannis \& Campbell, 2009; Papa et al., 2018). Therefore, the focus on external knowledge acquisition can help factories to rebuild themselves technologically, recognizing that new business models are both feasible and actionable through the discovery of new attributes and risks in highly uncertain environments (Choi et al., 2008; McGraith \& MacMillan, 2009; Chesbrough, 2010).

With this in mind, exploration and exploitation of innovation - normally focused on the product and service offered - are further integrated into existing business models. By doing this, we can continuously screen and analyze business models by experimenting with manufacturing modulation (adjusting the value chain compared with the surrounding environment, i.e. frequent modulations coming from customers' feedback) and influencing consumer preferences (not only with current products, but also providing new products and services).

Making the shift from competition to co-opetition is surely the first step toward the re-engineering of smart factories (Tsai, 2002). It means implicitly leaning on knowledge management and technological innovation as two main paradigms that endogenously affect business organizations.

Clearly, the present study is not exempt from limitations, due to its interpretative nature. The first limitation is linked the use of a single-case methodology. Whilst it has generated a considerable number of implications supported by a coherent literature review, it lacks of reliability. This makes it difficult to replicate our findings. Finally, while the originality of the questions explored in relation to the 
research gap represents a strong point for the study, it also makes the research theoretically vulnerable, as there is no clear pathway in terms of the literature concerning the subject.

Thus, starting from the results related to the case proposed, further investigation could be extended to more business realities, particularly through a multiple casestudy approach.

However, managerial research in this field is scarce even if smart manufacturing is not a new phenomenon. Even so, most related studies discuss the improvement of operations and engineering processes, whilst only a little scholarship adopts a different perspective regarding lean applicability in the knowledge work process.

Although academic work has been lacking in this objective, more and more companies have taken beginning steps to make their organization smarter. In this way, future work should include longitudinal perspectives and comparative analyses as well. In addition, it would be interesting to empirically verify, through the use of structural quantitative methods, the relationship between various aspects involved in the digitalization (i.e. human resource management, innovation performance, ambidexterity, supply chain, etc.) aiming at generating new scholarly and managerial insights. More studies will also focus on specific knowledge work environments, especially ones involving knowledge-intensive work.

\section{Bibliography}

Antikainen, R., \& Lönnqvist, A. (2006). Knowledge Work Productivity Assessment. Institute of Industrial Management. Tampere University of Technology. PO Box, 541, 79-102.

Ardichvili, A., Cardozo, R., \& Ray, S. (2003). A Theory of Entrepreneurial Opportunity Identification and Development. Journal of Business Venturing, 18(1), 105-123.

\section{https://doi.org/10.1016/S0883-9026(01)00068-4}

Barbuto Jr, J. E. (2005). Motivation and Transactional, Charismatic, and Transformational Leadership: A Test of Antecedents. Journal of Leadership \& Organizational Studies, 11(4), 2640.

\section{https://doi.org/10.1177/107179190501100403}

Barney, J. B. (2001). Resource-Based Theories of Competitive Advantage: A Ten-Year Retrospective on the Resource-Based View. Journal of Management, 27(6), 643-650.

https://doi.org/10.1016/S0149-2063(01)00115-5

Berchicci, L. (2013). Towards an Open R\&D System: Internal R\&D Investment, External Knowledge Acquisition and Innovative Performance. Research Policy, 42(1), 117-127.

\section{https://doi.org/10.1016/j.respol.2012.04.017}

Black, J. T. (1991). The Design of the Factory with a Future. New York, NYC, McGraw-Hill.

Bonfanti, A., Del Giudice, M., \& Papa, A. (2015). Italian Craft Firms Between Digital Manufacturing, Open Innovation, and Servitization. Journal of the Knowledge Economy, 1, 1-14.

https://doi.org/10.1007/s13132-015-0325-9

Brondoni, S. M., (2011) Global Networks, Knowledge Management and World Cities, Symphonya. Emerging Issues in Management (symphonya.unimib.it), (1), 7-18 http://dx.doi.org/10.4468/2011.1.02brondoni

Brondoni, S. M., (2015) Global Networks, Outside-In Capabilities and Smart Innovation, Symphonya. Emerging Issues in Management (symphonya.unimib.it), (1), 6 - 21 .

http://dx.doi.org/10.4468/2015.1.02brondoni 
Carayannis, E. G., \& Campbell, D. F. (2009). "Mode 3" and "Quadruple Helix": Toward a 21st Century Fractal Innovation Ecosystem. International Journal of Technology Management, 46(34), 201-234.

\section{https://doi.org/10.1504/IJTM.2009.023374}

Chen, I. J., \& Popovich, K. (2003). Understanding Customer Relationship Management (CRM) People, Process and Technology. Business Process Management Journal, 9, (5), 672-688.

https://doi.org/10.1108/14637150310496758

Chesbrough, H. W. (2006). Open Innovation: The New Imperative for Creating and Profiting from Technology. Harvard Business Press, New York., NY.

Chesbrough, H. W. (2010). Business Model Innovation: Opportunities and Barriers. Long Range Planning, 43(2), 354-363.

https://doi.org/10.1016/j.1rp.2009.07.010

Choi, B., Poon, S. K., \& Davis, J. G. (2008). Effects of Knowledge Management Strategy on Organizational Performance: A Complementarity Theory-Based Approach. Omega, 36(2), 235251.

https://doi.org/10.1016/j.omega.2006.06.007

D'aveni, R. A. (2010). Hypercompetition. Simon and Schuster, New York, NY.

Datta, D. K., Guthrie, J. P., \& Wright, P. M. (2005). Human Resource Management and Labor Productivity: Does Industry Matter?. Academy of Management Journal, 48, (1), 135-145.

https://doi.org/10.5465/amj.2005.15993158

Davis, J., Edgar, T., Porter, J., Bernaden, J., \& Sarli, M. (2012). Smart Manufacturing, Manufacturing Intelligence and Demand-Dynamic Performance. Computers \& Chemical Engineering, 47, 145-156.

https://doi.org/10.1016/j.compchemeng.2012.06.037

Del Giudice, M., \& Straub, D. (2011). Editor's Comments: It and Entrepreneurism: An On-Again, Off-Again Love Affair or a Marriage?. MIS Quarterly, 35(4), 3-8.

Del Giudice, M., Carayannis, E. G., \& Maggioni, V. (2017). Global Knowledge Intensive Enterprises and International Technology Transfer: Emerging Perspectives from A Quadruple Helix Environment. Journal of Technology Transfer, 42(2), 229-235.

https://doi.org/10.1007/s10961-016-9496-1

Dezi L., Pisano P., Pironti M., \& Papa A. (2018), Unpacking Open Innovation Neighbourhoods: Le milieu of the Lean SmartCity. Management Decision, Dezi L., Pisano P., Pironti M., \& Papa A. (2018), Unpacking Open Innovation Neighbourhoods: Le milieu of the Lean SmartCity. Management Decision, 56, (6), 1247-1270.

https://doi.org/10.1108/MD-04-2017-0407

Drucker, P. F. (1993). Managing for the Future. Routledge, New York, NY.

Drucker, P. F. (1999). Knowledge-worker productivity: The Biggest Challenge. California management review, 41, (2), 79-94.

https://doi.org/10.1109/EMR.2006.1679053

Eisenhardt, K. M. (1989). Building Theories from Case Study Research. Academy of Management Review, 14, (4), 532-550.

https://doi.org/10.5465/amr.1989.4308385

Evans, P. B. (2012). Embedded Autonomy: States and Industrial Transformation. Princeton University Press, New York.

Filippini, R., Güttel, W. H., \& Nosella, A. (2012). Ambidexterity and the Evolution of Knowledge Management Initiatives. Journal of Business Research, 65, (3), 317-324.

https://doi.org/10.1016/j.jbusres.2011.04.003

Freedman, S. (1999). An Overview of Fully Integrated Digital Manufacturing Technology. Simulation Conference Proceedings, 1999 Winter. IEEE, 1, (1), 281-285.

https://doi.org/10.1109/WSC.1999.823085 
Friess, P. (2013). Internet of Things: Converging Technologies for Smart Environments and Integrated Ecosystems. River Publishers, New York, NY.

Galbraith, J. R. (2011). Designing the Customer-Centric Organization: A Guide to Strategy, Structure, and Process. John Wiley \& Sons, New York, NY.

George, G., \& Bock, A. J. (2011). The Business Model in Practice and its Implications for Entrepreneurship Research. Entrepreneurship Theory and Practice, 35, (1), 83-111.

https://doi/full/10.1111/j.1540-6520.2010.00424

Grant, R. M. (1991). The Resource-Based Theory of Competitive Advantage: Implications for Strategy Formulation. California Management Review, 33, (3), 114-135.

https://doi.org/10.1016/B978-0-7506-7088-3.50004-8

Grant, R. M. (1996). Toward a Knowledge-Based Theory of the Firm. Strategic Management Journal, 17, (2), 109-122.

https://doi.org/10.1002/smj.4250171110

Gupta, B., Iyer, L. S., \& Aronson, J. E. (2000). Knowledge Management: Practices and Challenges. Industrial Management \& Data Systems, 100, (1), 17-21.

https://doi.org/10.1108/02635570010273018

Harrison, A. (1992). Just-in-Time: Manufacturing in Perspective. Prentice Hall.

Iivari, J., \& Linger, H. (1999, January). Knowledge Work as Collaborative Work: A Situated Activity Theory View. Systems Sciences, 1999. HICSS-32. Proceedings of the 32nd Annual Hawaii International Conference on, IEEE, 10-18.

https://doi.org/10.1109/HICSS.1999.772702

Kearns, G. S., \& Lederer, A. L. (2003). A Resource- Based View of Strategic It Alignment: How Knowledge Sharing Creates Competitive Advantage. Decision Sciences, 34, (1), 1-29.

https://doi.org/10.1111/1540-5915.02289

Kuratko, D. F., \& Audretsch, D. B. (2009). Strategic Entrepreneurship: Exploring Different Perspectives of an Emerging Concept. Entrepreneurship Theory and Practice, 33, (1), 1-17.

https://doi.org/10.1111/j.1540-6520.2008.00278.x

Kuratko, D. F., Hornsby, J. S., \& Goldsby, M. G. (2007). The Relationship of Stakeholder Salience, Organizational Posture, and Entrepreneurial Intensity to Corporate Entrepreneurship. Journal of Leadership \& Organizational Studies, 13, (4), 56-72.

https://doi.org/10.1177/10717919070130040801

Laihonen, H., Jääskeläinen, A., Lönnqvist, A., \& Ruostela, J. (2012). Measuring the Productivity Impacts of New Ways of Working. Journal of Facilities Management, 10, (2), 102-113.

https://doi.org/10.1108/14725961211218749

Lasi, H., Fettke, P., Kemper, H. G., Feld, T., \& Hoffmann, M. (2014). Industry 4.0. Business \& Information Systems Engineering, 6(4), 239-242.

https://doi.org/10.1007/s12599-014-0334-4

Lee, J., Bagheri, B., \& Kao, H. A. (2015). A Cyber-Physical Systems Architecture for Industry 4.0Based Manufacturing Systems. Manufacturing Letters, 3, 18-23.

https://doi.org/10.1016/j.mfglet.2014.12.001

Leonard- Barton, D. (1992). Core Capabilities and Core Rigidities: A Paradox in Managing New Product Development. Strategic Management Journal, 13(1), 111-125.

https://doi.org/10.1002/smj.4250131009

Mark, G., \& Semaan, B. (2008, November). Resilience in Collaboration: Technology as a Resource for New Patterns of Action. Proceedings of the 2008 ACM conference on Computer supported cooperative work, ACM, 137-146.

https://doi.org/10.1145/1460563.1460585

Mårtensson, M. (2000). A Critical Review of Knowledge Management as a Management Tool. Journal of Knowledge Management, 4(3), 204-216.

https://doi.org/10.1108/13673270010350002 
McGrath, R. G., \& MacMillan, I. C. (2009). Discovery-driven Growth: A Breakthrough Process to Reduce Risk and Seize Opportunity. Harvard Business Press, New York, NY.

Meso, P., \& Smith, R. (2000). A Resource-Based View of Organizational Knowledge Management Systems. Journal of Knowledge Management, 4, (3), 224-234.

https://doi.org/10.1108/13673270010350020

Mills, J. (2002). Strategy and Performance: Creating a Winning Business Formula. Cambridge University Press, UK.

Mital, M., Choudhary, P., Chang, V., Papa, A., \& Pani, A. K. (2017), Adoption of Internet of Things in India: A Test of Competing Models Using a Structured Equation Modeling Approach. Technological Forecasting and Social Change.

https://doi.org/10.1016/j.techfore.2017.03.001

Morris, M. H., \& Sexton, D. L. (1996). The Concept of Entrepreneurial Intensity: Implications for Company Performance. Journal of Business Research, 36, (1), 5-13.

https://doi.org/10.1016/0148-2963(95)00158-1

Murray, A., Papa, A., Cuozzo, B., \& Russo, G. (2016), Evaluating the Innovation of the Internet of Things: Empirical Evidence from the Intellectual Capital Assessment. Business Process Management Journal, 22, (2), 341-356.

https://doi.org/10.1108/BPMJ-05-2015-0077

Nelson, R. R., \& Winter, S. G. (1982). The Schumpeterian Tradeoff Revisited. American Economic Review, 72, (1), 114-132.

http://www.jstor.org/stable/1808579

O'Reilly 3rd, C. A., \& Tushman, M. L. (2004). The Ambidextrous Organization. Harvard Business Review, 82, (4), 74-81.

O’Reilly, C. A., \& Tushman, M. L. (2008). Ambidexterity as a Dynamic Capability: Resolving the Innovator's Dilemma. Research in Organizational Behavior, 28, 185-206.

https://doi.org/10.1016/j.riob.2008.06.002

Osterwalder, A., \& Pigneur, Y. Business Model Generation: A Handbook for Visionaries, Game Changers, and Challengers. John Wiley \& Sons, 2010.

Papa, A., Dezi, L., Gregori, G. L., Mueller, J., \& Miglietta, N. (2018). Improving Innovation Performance through Knowledge Acquisition: The Moderating Role of Employee Retention and Human Resource Management Practices. Journal of Knowledge Management.

https://doi.org/10.1108/JKM-09-2017-0391

Paton, D. J., Sumption, K. J., \& Charleston, B. (2009). Options for Control of Foot-And-Mouth Disease: Knowledge, Capability and Policy. Philosophical Transactions of the Royal Society B: Biological Sciences, 364, (1530), 2657-2667.

https://doi.org/10.1098/rstb.2009.0100

Penrose, E. T. (2009). The Theory of the Growth of the Firm. Oxford University Press.

Pisano, P., Pironti, M., Tirabeni, L., \& Sola, D. (2016). Nuovi Modelli di Business e Tecnologie Digitali: Il Ruolo delle Telco da Piattaforma Abilitante a Player Strategico nella Fabbrica 4.0. Management in a Digital World. Decisions, Production, Communication.

https://doi.org/10.7433/SRECP.FP.2016.20

Porter, M. E. (2008). The Five Competitive Forces That Shape Strategy. Harvard Business Review, $86,(1), 25-40$.

Raisch, S., Birkinshaw, J., Probst, G., \& Tushman, M. L. (2009). Organizational Ambidexterity: Balancing Exploitation and Exploration for Sustained Performance. Organization Science, 20, (4), 685-695.

https://doi.org/10.1287/orsc.1090.0428

Ray, C. A. (1989). Skill Reconsidered: The Deskilling and Reskilling of Managers. Work and Occupations, 16, (1), 65-79.

https://doi.org/10.1177/0730888489016001004 
Reeves, M., Zeng, M., \& Venjara, A. (2015). The Self-Tuning Enterprise. Harvard Business Review, 93, (6), 77-83.

Rieple, A., Pironti, M., \& Pisano, P. (2012), Business Network Dynamics and Diffusion of Innovation, Symphonya. Emerging Issues in Management (symphonya.unimib.it), (2), 13-25.

http://dx.doi.org/10.4468/2012.2.02rieple.pironti.pisano

Romano M., Nicotra M., Papa A., Castello E. (2018), Financial Management of Publicly Funded Research Activities: An Explorative Study, Int. J. Managerial and Financial Accounting, http://dx.doi.org/10.1504/IJMFA.2018.10011746

Santoro, G., Vrontis, D., Thrassou, A., \& Dezi, L. (2017). The Internet of Things: Building a Knowledge Management System for Open Innovation and Knowledge Management Capacity. Technological Forecasting and Social Change.

https://doi.org/10.1016/j.techfore.2017.02.034

Škerlavaj, M., Dimovski, V., \& Desouza, K. C. (2010). Patterns and Structures of IntraOrganizational Learning Networks within a Knowledge-Intensive Organization. Journal of Information Technology, 25(2), 189-204.

https://doi.org/10.1057/jit.2010.3

Staats, B. R., Brunner, D. J., \& Upton, D. M. (2011). Lean Principles, Learning, and Knowledge Work: Evidence from a Software Services Provider. Journal of Operations Management, 29(5), 376-390.

https://doi.org/10.1016/j.jom.2010.11.005

Swanson, C. A., \& Lankford, W. M. (1998). Just-in-Time Manufacturing. Business Process Management Journal, 4(4), 333-341.

https://doi.org/10.1108/14637159810238246

Teece, D. J. (1998). Capturing Value from Knowledge Assets: The New Economy, Markets for Know-How, and Intangible Assets. California Management Review, 40(3), 55-79.

https://doi.org/10.2307/41165943

Toussaint, J. S., \& Berry, L. L. (2013). The Promise of Lean in Health Care. Mayo Clinic Proceedings, January, 88, (1), 74-82.

https://doi.org/10.1016/j.mayocp.2012.07.025

Tsai, W. (2002). Social Structure of "Coopetition" within a Multiunit Organization: Coordination, Competition, and Intraorganizational Knowledge Sharing. Organization Science, 13(2), 179-190.

https://doi.org/10.1287/orsc.13.2.179.536

Vrontis, D., Thrassou, A., Santoro, G., \& Papa, A. (2017). Ambidexterity, External Knowledge and Performance in Knowledge-Intensive Firms. Journal of Technology Transfer, 42(2), 374-388.

https://doi.org/10.1007/s10961-016-9502-7

Westkämper, E. (2007). Digital Manufacturing in the Global Era. In Digital Enterprise Technology, 3-14. Springer US, New York, NY.

Zikopoulos, P., \& Eaton, C. (2011). Understanding Big Data: Analytics for Enterprise Class Hadoop and Streaming Data. McGraw-Hill Osborne Media.

Zott, C., \& Amit, R. (2008). The Fit between Product Market Strategy and Business Model: Implications for Firm Performance. Strategic Management Journal, 29(1), 1-26.

https://doi.org/10.1002/smj.642

Zott, C., Amit, R., \& Massa, L. (2011). The Business Model: Recent Developments and Future Research. Journal of Management, 37(4), 1019-1042.

https://doi.org/10.1177/0149206311406265

Zuehlke, D. (2010). SmartFactory-Towards a Factory-Of-Things, Annual Reviews in Control, 34(1), 129-138.

https://doi.org/10.1016/j.arcontrol.2010.02.008 